\title{
Contribution of experimental fluid mechanics to the design of vertical slot fish passes
}

\author{
R.W. Wang ${ }^{(1)}$, L. David ${ }^{(1)}$, M. Larinier ${ }^{(2)}$ \\ Received October 23, 2009 / Reçu le 23 octobre 2009 \\ Accepted January 5, 2010 / Accepté le 5 janvier 2010
}

\begin{abstract}
Key-words: vertical slot fish pass, flow topology, velocity field, turbulent kinetic energy
\end{abstract}

\section{ABSTRACT}

This paper presents the main results of an experimental study of mean and turbulent characteristics of flow in a scale model of a vertical slot fish pass with varying width and slope (from 5\% to 15\%). Experimental hydraulic modelling was combined with the study of fish behaviour in the model. The discharge coefficient, which significantly affects the design of such facilities, varied from 0.67 to 0.89 and was strongly influenced by the slope. Two distinct flow patterns were observed, depending on the slope and the fish pass width. The point of transition between the two states was determined. Low velocity areas are likely resting zones for fish and particular attention was paid to evaluating these areas. Slope was found to affect both the volume of the low velocity zone, and the value of turbulent kinetic energy in these areas. The statistical characteristics of turbulent kinetic energy in the pools were linked primarily to the maximum velocity in the jet. An analysis of the behaviour of juvenile brown trout (Salmo trutta) in the scale model clearly showed that the fish avoided the areas of high velocities in the jet, except at the slot itself where they took advantage of the jet's non-stationary character. Low-velocity areas were not frequented uniformly by fish, which stayed most frequently in the zone located just downstream from the slot and behind the small side baffle. It is suggested that future studies might investigate lower pool-length to slot-width ratios, which might make it possible to increase the slope significantly and should also examine ways of improving hydraulic conditions for fish by carefully distributing obstacles in pools.

\section{RÉSUMÉ}

Contribution de la mécanique des fluides expérimentale à la conception des passes à poissons à fentes verticales

Mots-clés : passe à fentes verticales, topologie d'écoulement,
Cet article présente les résultats d'une étude expérimentale sur les caractéristiques moyennes et turbulentes de l'écoulement dans une passe à fentes verticales de pente variant de $5 \%$ à $15 \%$ et de largeur variable. L'étude hydraulique a été complétée par l'observation du comportement du poisson sur le modèle. Les valeurs du coefficient de débit intervenant dans le dimensionnement des passes varient de 0,67 à 0,89 et sont très sensibles à la pente. La transition entre les

(1) Institut PPRIME, CNRS-Université de Poitiers-ENSMA, UPR 3346, Axe HydEE, Boulevard Marie et Pierre Curie, Téléport 2, BP 30179, 86962 Futuroscope Cedex, France, ruey-wen.wang@lea.univ-poitiers.fr, laurent.david@lea.univ-poitiers.fr

(2) ONEMA, Pôle Écohydraulique, Institut de Mécanique des Fluides de Toulouse, Allée du Professeur Camille Soula, 31400 Toulouse, France, michel.larinier@imft.fr 
champ de vitesse, énergie cinétique turbulente deux configurations de l'écoulement observées a été déterminée, en fonction de la pente et de la largeur. Les caractéristiques de l'énergie cinétique turbulente, en particulier dans les zones à faibles vitesses, ont été déterminées. La pente affecte à la fois le volume des zones à faible vitesse et la valeur de l'énergie cinétique turbulente dans ces zones qui sont susceptibles de servir de zone de repos aux poissons. Les caractéristiques statistiques de l'énergie cinétique dans les bassins sont avant tout liées à la vitesse maximale dans le jet. L'analyse du comportement de juvéniles de truites (Salmo trutta) dans le modèle montre très clairement que le poisson évite les zones à fortes vitesses, en particulier le jet, sauf évidemment au niveau de la fente qu'il franchit en mettant à profit le caractère instationnaire du jet. Les zones à faibles vitesses ne sont pas fréquentées de façon identique, le poisson utilisant pour stationner le plus fréquemment la zone située à l'aval du déflecteur de paroi. Les résultats et la discussion suggèrent que les études futures portent sur des rapports de forme longueur de bassin sur largeur de fente plus faibles pour augmenter la pente des ouvrages de façon significative et se poursuivent sur l'amélioration des conditions d'écoulement par la mise en place d'obstacles dans les bassins.

\section{INTRODUCTION}

The restoration of longitudinal connectivity for fish is now a major issue for regulated rivers. Decommissioning and removing obstacles, i.e. dams or weirs, is the most radical and most sustainable way of restoring free passage for migratory fish. However, this solution is often expensive or impractical, and can only be applied to obstacles which are no longer of any use. On many obstructions, the only way to restore connectivity, at least partly, is to build a fish passage facility.

Pool fish passes with vertical slots are one of the types that have been frequently used to allow upstream migration for both diadromous (i.e. whose migration occurs between freshwater and marine environment) and potamodromous species (i.e. whose migration occurs entirely in fresh water). Although their design criteria are quite well understood, there is still plenty of room for improvement to make these passes both more efficient and more capable of accommodating a wider range of species, particularly small species (length $<80-100 \mathrm{~mm}$ ), while also reducing their cost.

Vertical slot fishways (VSFs) are based on the principle of dividing the height to be passed into several small drops forming a series of pools. The passage of water from one pool to another is provided via a deep slot located in the cross-wall separating two pools. The water flow forms a jet at the slot and the energy of the jet is dissipated by mixing in the pool.

The principal or critical parameters of a pool fish pass are the dimensions of the pools, the geometric characteristics of the cross-walls separating the pools (shape, dimensions of the slots and the baffles) and the slope. These geometric characteristics, together with the water levels upstream and downstream of the facility, determine the hydraulic behaviour of the pass, i.e. the flow discharge, the difference in water level from one pool to another, the flow pattern and the velocity field within the pools. The length $(L)$ and width $(B)$ of the pools can vary respectively from 7 to 12 and from 5 to more than 9 times the width (b) of the slot. The variability of these ratios at existing fish passes is linked to the characteristics and constraints of the site where the fish pass had to be built (generally the limitation of the total length of the facility on existing obstructions), the flow discharge passing through the facility and the compliance with specifications for volumetric power dissipation, which is a crude assessment of turbulence level in the pools. This variability results in a certain diversity in flow patterns that can be observed in existing fish passes. These flow patterns are one of the elements determining the capacity of the facility to allow the target species to pass successfully.

The flow field in several designs of VSFs was studied experimentally by Rajaratnam et al. $(1986,1992)$ and Lenne in Larinier (1992) in order to test the sensitivity of the hydraulic performance of VSFs to changes in the geometry of the baffles and the dimensions of the pools, 
and to develop effective yet simple designs. The former recommended three particular designs, based on overall hydraulic performance and simplicity in construction, all three designs being characterised by constant $B / b$ and $L / b$ ratios (respectively 8 and 10 ). The latter proposed a simplified design with lower $B / b$ and $L / b$ values (respectively 6.63 and 8.1 ).

The main design criteria for a vertical slot fish pass are the maximum head difference between pools, or drop $(\Delta H)$, which determines the maximum velocity in the pools, and the maximum volumetric dissipated power $P_{v}$ - or EDF, Energy Dissipation Factor in the USA (Bates, 2000) which is a general indicator of the turbulence and agitation level in the pools. $P_{v}$ (in $\mathrm{W} \cdot \mathrm{m}^{-3}$ ) can be expressed as $P_{V}=\rho g Q \Delta H / \mathrm{Nol}$, where $\rho$ is the density of water $\left(1000 \mathrm{~kg} \cdot \mathrm{m}^{-3}\right), g$ the acceleration due to gravity $\left(9.8 \mathrm{~m} \cdot \mathrm{s}^{-2}\right), Q$ the flow discharge in the facility $\left(\mathrm{m}^{3} \cdot \mathrm{s}^{-1}\right)$ and $\mathrm{Vol}$ the volume of water in the pool $\left(\mathrm{m}^{3}\right)$.

The selection of the drop depends on the swimming capacities of the fish. It can vary from less than $0.10 \mathrm{~m}$ for fish passes specifically designed for small species to more than $0.30 \mathrm{~m}$ for trout or large diadromous species such as salmon or sea trout. The criterion used for $P_{V}$ is a purely empirical one. The value of $200-250 \mathrm{~W} \cdot \mathrm{m}^{-3}$ is generally taken as the upper limit for salmonids (Bates, 2000; Larinier et al., 2002); lower levels are recommended (100$150 \mathrm{~W} \cdot \mathrm{m}^{-3}$ ) for shad and rheophilic riverine species (Larinier et al., 2002). Even lower values (around $40-50 \mathrm{~W} \cdot \mathrm{m}^{-3}$ ) have been adopted to enable upstream passage pass of all fish with length $>90 \mathrm{~mm}$ and approximately half of the fish between 20-70 $\mathrm{mm}$ on the Murray-Darling basin in Australia (Barrett and Mallen-Cooper, 2006; Stuart et al., 2008).

This commonly-used criterion based on $P_{v}$ values was proposed in the 1980s (Larinier, 1983; Bell, 1986) when there was no simple technical means for measuring the characteristics of turbulence in pools. This metric has the main advantage of being readily accessible by calculation. However, it is not exactly known what it corresponds to physically in terms of turbulence characteristics in the pools. Nowadays, the use of more sophisticated measurement techniques such as Particle Image Velocimetry (PIV) and Acoustic Doppler Velocimetry (ADV) allows us to measure the average and turbulent characteristics of flows more easily. Several experimental studies have been carried out recently using microacoustic velocimeters (Puertas et al., 2004; Liu et al., 2006) to measure velocities and different turbulence parameters in VSFs.

A detailed experimental investigation was undertaken in the Institut PPRIME (France) in order to better characterize the flow pattern in the pools of a vertical fish pass, particularly the areas of low velocity which are considered to be resting zones for fish. The objective was to try to relate the empirical concept of volumetric dissipated power to the mean flow and turbulence characteristics of the flow in the pools.

The velocity measurements were carried out mainly by PIV but also by ADV. These measurements were used to determine the various kinematic parameters characterising the flow for different slopes, discharges and geometry of pools: time-averaged velocities and flow topologies, fluctuating velocities, turbulent kinetic energy, vorticity, etc.

This work on flow characterization was supplemented by observations of the behaviour of small fish in the pools, which made it possible to identify the path chosen by fish moving from one pool to another and the specific resting zones actually exploited by the fish.

It is difficult to monitor in detail the behaviour of a fish in a fish pass in situ. In a prototype fish pass, different methods of marking (pit tags or telemetry) have been used to estimate the time needed for an individual to cross one or more pools (Stuart et al., 2008). However, these methods do not enable the monitoring of actual fish behaviour in pools, in particular to track their path and the way they use the different flow zones in the pools. Until now there has been no means of determining whether fish use particular zones in pools more than any other, with the exception of visual observation near the surface or qualitative observation by means of DIDSON high-definition sonar (Stuart et al., 2008). While it is extremely difficult to get behavioural data in prototype fish passes, it seems to be possible to use juveniles as substitutes for adult fish in a scale model in order to obtain basic information on fish behavioural response. This assumption, based on the fact that individuals that are similar as regards the shape of their body and fins will have similar behaviours when they are in a similar 

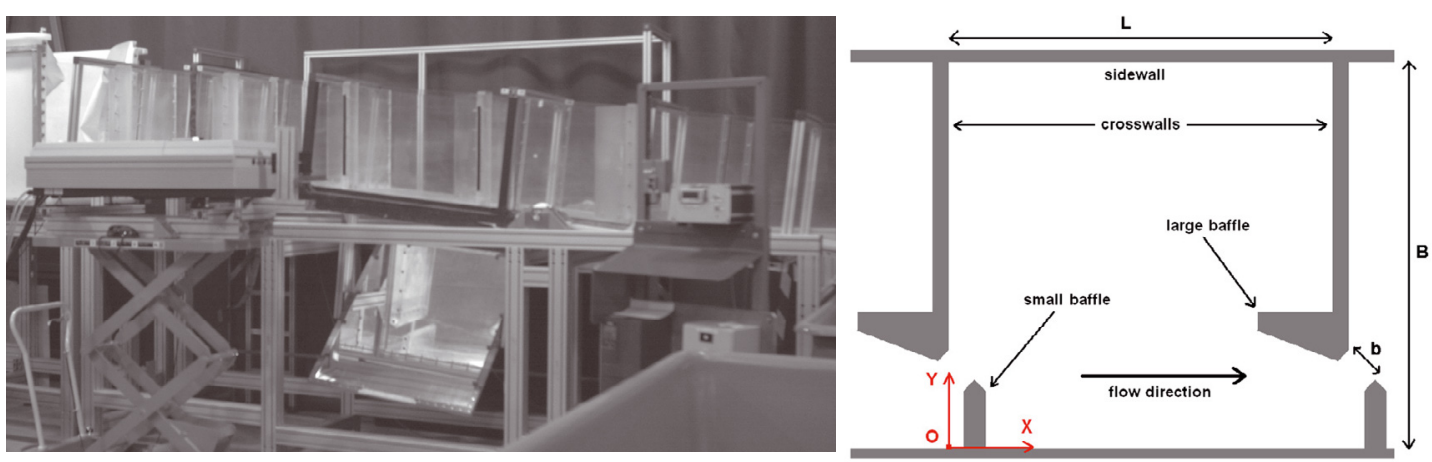

Figure 1

Experimental device and pool configuration.

Figure 1

Dispositif expérimental et configuration des bassins.

environment, has been used for the development and the optimization of fish passes on scale models before testing the effectiveness with prototypes (Guiny et al., 2005; Kynard et al., 2008).

This paper attempts to extract the practical results from the tests carried out in the Institut PPRIME and to present in a simple and pragmatic way so that they can be used by engineers or biologists when designing a VSF. For a more comprehensive overview of the hydraulic results, the reader is directed to the papers of Tarrade et al. $(2006,2008)$.

\section{MATERIAL AND METHODS}

\section{> EXPERIMENTAL SETUP}

For this experimental study the geometry of the physical model used was based on an analysis of the geometry of VSFs built in France over the last 20 years, from which we defined an 'average' geometry. The vertical slot fishway model consisted of five pools, $L=0.75 \mathrm{~m}$ long and $H=0.55 \mathrm{~m}$ deep installed in a plexiglass flume (Figure 1). The width of the slot is $b=0.075 \mathrm{~m}$. The model and the prototype are related by the Froude similitude, on a geometrical scale, depending on the dimensions of the prototype pools, between 1/2.5 (for a small trout fish pass) and approximately $1 / 6$ (for a large fish pass for shad and large diadromous species).

The width of the pools $(B)$ was varied from $0.675 \mathrm{~m}$ to $0.425 \mathrm{~m}$. Three flow discharges in the fish pass were tested $\left(18,23\right.$, and $\left.27 \mathrm{~L} \cdot \mathrm{S}^{-1}\right)$ and the flume slope in this study was varied from $5 \%$ to $15 \%$. These values of slope encompass the most commonly used slopes of fish passes, which can vary from less than $7 \%$ for a large fishway for diadromous species to more than $12 \%$ for a small trout fish pass. The cross-walls between pools were set vertically within the flume when the floor slope was at $10 \%$.

\section{$>$ METHODOLOGY}

Experiments were performed with uniform flow conditions in the fish pass, i.e. when the tailwater depth, adjusted by means of a slide gate, was such that the average depth in each pool (measured at its centre) was the same for (almost) all the pools. The experimental measurements were taken in the third pool in order to ensure an established flow. Water depths were measured near the centreline of the pools. Flow discharge was measured by means 
of a magnetic flowmeter installed in the water supply line. Velocity measurements were taken by means of Particle Image Velocimetry (PIV) in two planes parallel to the channel bed of the fishway $(2 \mathrm{~cm}$ and $15 \mathrm{~cm}$ from the bottom). The PIV acquisition and treatment system was composed of a Nd-Yag double-cavity laser for lighting a section of flow, a system of two cameras recording the whole pool, and a synchronization module. Velocity fields were evaluated by computing multi-pass cross-correlation with window deformation between two successive images with the two velocity fields being merged to obtain a single field on each occasion. The accuracy of measurements was better than $5 \%$ in the main parts of the pool, but the 3D effect inside the jet close to the slot strongly affected this accuracy. In addition, measurements with a better spatial resolution near to the slot provided maximum velocity values that closely matched the velocity calculated from the water drop (Tarrade, 2007).

The flow topology for the different widths and for slopes $=5 \%, 10 \%$ and $15 \%$ was obtained by PIV measurement; the topology for the intermediate slopes and widths was observed by both flow visualization and ADV measurements using a Micro ADV SonTek probe. The sensor was composed of one transmitter and three receivers which were aligned to intersect with the transmit beam at a small sampling volume located about $50 \mathrm{~mm}$ from the probe tip. The sampling volume was a cylinder of diameter $4.5 \mathrm{~mm}$ and height $5.6 \mathrm{~mm}$. The sampling time for the ADV was set at 5 min with a sampling frequency of $50 \mathrm{~Hz}$. A cutoff when correlation was at 0.7 and Phase-space Threshold Despiking were used as filters (Sontek, 1997; Wahl, 2000; Goring and Nikora, 2002).

\section{> FISH BEHAVIOUR}

A series of biological experiments were conducted between 2004 and 2008 using the same model. Slope used was $10 \%$, while discharge was $Q=23 \mathrm{~L} \cdot \mathrm{S}^{-1}$ and width of pool was $B=0.675 \mathrm{~m}$. Farmed juvenile brown trout (Salmo trutta, length range: $80-120 \mathrm{~mm}$ ) were used in this study. They were held in a circular tank with constant flow for at least $24 \mathrm{~h}$ between tests for recovery, and a maximum of six tests were performed with the same fish. Fish were held in the VSF experimental flume for 90 min before each test to allow them to adapt to the flow. The mean temperature of the water in the flume was $17.9^{\circ} \mathrm{C}$ (range $16-19{ }^{\circ} \mathrm{C}$ ). The fish behaviour was continually recorded by video with a camera located under the floor of the third pool. This allowed digitization of fish location with time. Groups of 20-30 fish were introduced at the downstream end of the flume. Each batch of fish was left in the flume 90 min before being removed.

\section{RESULTS}

\section{> DEPTH-DISCHARGE RELATIONSHIP}

A knowledge of the relationship between the discharge and the average water depth in the pool is essential when dimensioning a VSF. Most studies carried out in hydraulics laboratories use a dimensionless relationship (Rajaratnam et al., 1986; Wu et al., 1999), linking a dimensionless discharge to the ratio of average depth to the slot width (b).

For this study a more practical relationship, that is used by engineers and in fish pass design software was preferred. The flow through a vertical slot fish pass is thus expressed by the formula (Bell, 1986; Andrew, 1990; Larinier, 1992):

$$
Q=C_{d} b\left(Z_{b}-Z_{s}\right) \sqrt{2 g \Delta H}=C_{d} b\left(H_{b}+0.5 L S\right) \sqrt{2 g L S}
$$

where $Q$ is flow discharge $\left(\mathrm{m}^{3} \cdot \mathrm{s}^{-1}\right), C_{d}$ the discharge coefficient of the slot, $b$ the width of the slot $(\mathrm{m}),\left(Z_{b}-Z_{s}\right)$ the head of water at the slot $(\mathrm{m}), g$ the acceleration due to gravity $\left(\mathrm{m} \cdot \mathrm{s}^{-2}\right)$, $\Delta H$ the drop between two adjacent pools $(\mathrm{m}), L$ the length of the pool $(\mathrm{m})$ and $S$ the slope of the fishway. The head $\left(Z_{b}-Z_{s}\right)$ is the difference between the water level elevation in the centre 


$$
B / b=5.67,6.67,7.67,9
$$

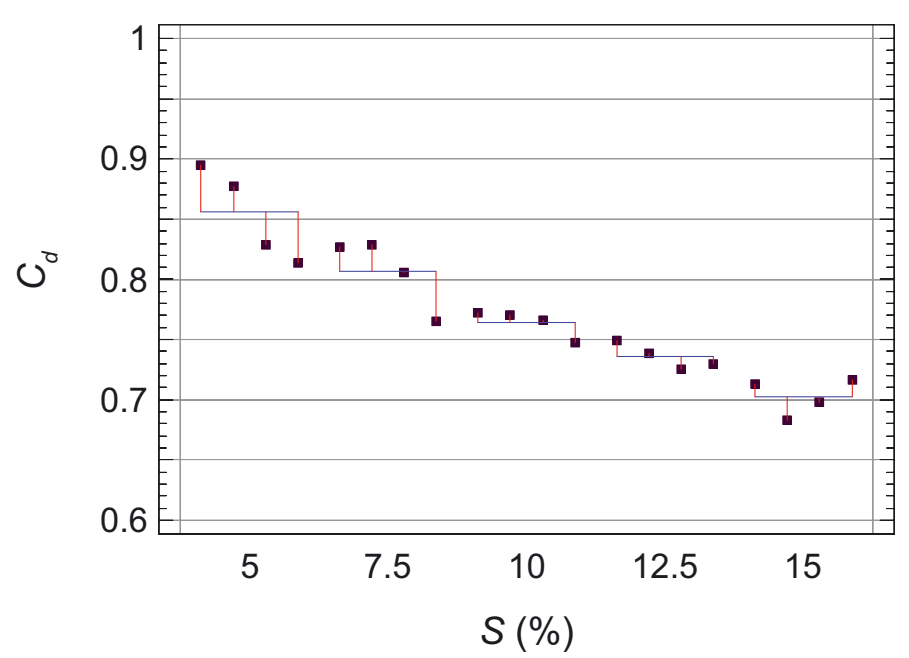

\section{Figure 2}

Variation of the coefficient of discharge $C_{d}$ with $S$ and B/b. For each slope, the coefficient of discharge is given for the different values of $B / b$ in increasing order.

\section{Figure 2 \\ Évolution du coefficient de débit $C_{d}$ en fonction de $S$ et $B / b$. Pour chaque pente, la valeur du coefficient de débit est donnée par ordre croissant de $B / b$.}

of a pool and that of the floor (or sill crest) level at the downstream slot; in the case of a regularly inclined floor and in the absence of any sill at the slot, it can be calculated by adding half of the drop, i.e. $\Delta H / 2$ (or $L S / 2$ ) to the measured water depth in the centre of the pool $H_{b}$. The experiments showed that values for the discharge coefficient $C_{d}$ varied between 0.67 and 0.89 . The value decreased when the slope increased: mean values were from 0.85 ( $5 \%$ slope) to 0.70 (15\% slope). The coefficient decreased with increasing pool width, from 0.79 (mean value for $B / b=5.67$ ) to 0.75 (mean value for $B / b=9$ ), this tendency being most marked for the lowest experimented slopes (Figure 2).

For the general expression of the volumetric dissipated power (see below) it is appropriate to use the water depth measured in the centre of the pool, $H_{b}$, as a reference and to express the flow discharge by the formula:

$$
Q=C_{m d} b H_{b} \sqrt{2 g L S} \text {. }
$$

The range of variation of this coefficient $C_{m d}$ was much lower than that for the $C_{d}$ discussed above and the mean values varied only between 0.90 (slope $5 \%$ ) and $0.87-0.88$ for the other slopes.

\section{> FLOW PATTERN AND MEAN VELOCITY FIELD IN THE POOLS}

The flow in the pools took the form of three distinct zones that varied in position and volume depending on the pass slope and the pool width: a jet from the slot that traverses the pool with decreasing velocity and two separate recirculation zones generated on each side of the jet. The recirculations which occur around an axis perpendicular to the channel bed, dissipate the energy of the jet in each pool. Two typical flow patterns can be observed, depending on the slope and the width of the pools.

In the first flow pattern (FP1), the principal flow leaving the slot enters the pools as a curved jet which opens out before converging again towards the next slot (Figure 3a; Figures 4a and 4c). The jet creates a large recirculation zone between the cross-walls on one side, occupying roughly half of the pool, and has an unsteady beating movement around the large baffle. 
(a)

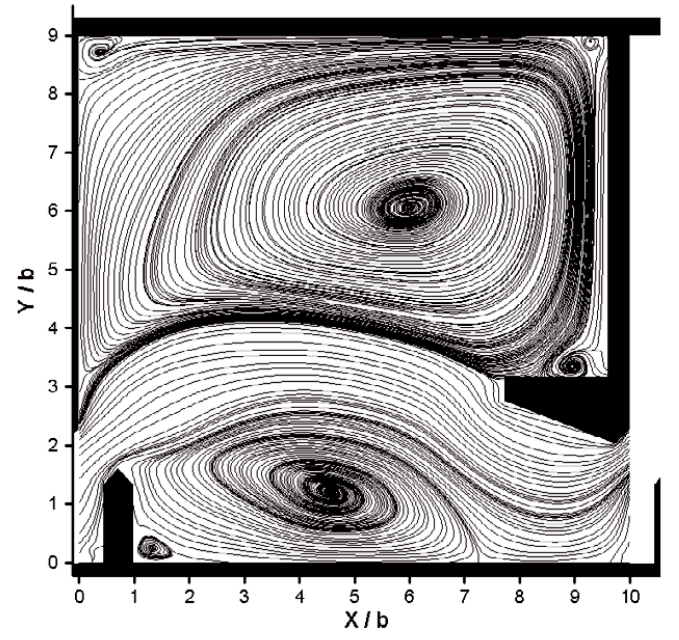

(b)

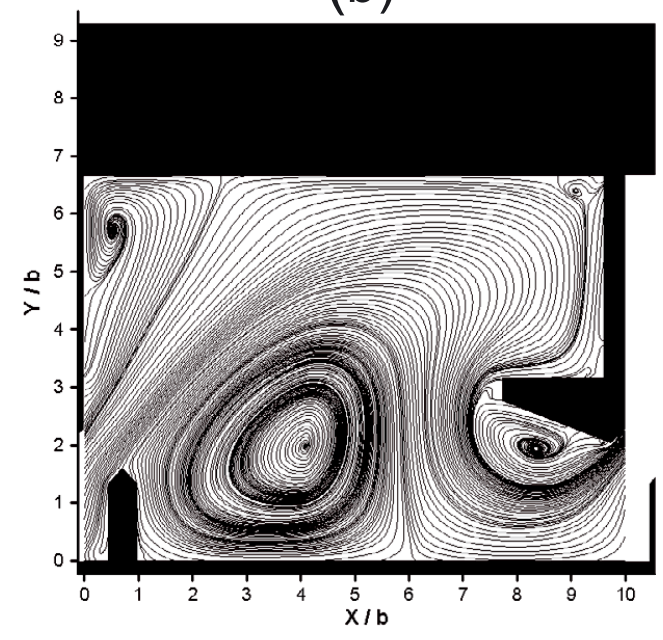

Figure 3

Topology of mean flow in the pool (FP1 on the left and FP2 on the right).

Figure 3

Topologie de l'écoulement moyen dans le bassin (FP1 à gauche et FP2 à droite).

In the second flow pattern (FP2) the jet has a very curved form and hits the opposite side wall (Figure 3b; Figure 4b). Two large contra-rotating swirls are then generated in the upstream corner of the pool and in the convex part of the jet, and a smaller one occurs close to the large baffle. When the slope is decreased, and correspondingly the maximum velocity of the jet is reduced, the impact of the jet at the opposite wall becomes much less obvious (Figure 4d).

The transition between the two types of flow pattern, illustrated in Figure 5, is not very clearcut. At the experimented ratio $L / b=10$ and for the lower slopes (5\% to $10 \%$ ), the transition between FP1 and FP2 takes place for a $B / b$ ratio of about 7-7.3. As the slope increases, the transition then takes place for increasing $B / b$ ratios (up to 7.7 to 8 ). The transition is quasiindependent of the flow discharge in the fish pass.

The flow patterns are very similar in the two measured planes and can be considered as independent of the height of the measurement section, depending only on the slope and the $B / b$ ratio. The 3D ADV measurements showed that the flow in such VSFs may in practice be regarded as quasi-two-dimensional, particularly in the recirculation areas where the vertical component of the velocity, $w$, is generally small compared to the other two components in longitudinal and transversal axes (Tarrade, 2007). However, visual observations show that the three-dimensional flow is more marked for the greatest slope and the lowest widths, where the jet hits the opposite side wall of the pool with higher velocities.

The measured maximum velocity in the core of the jet is very close to $\sqrt{2 g L S}$. The maximum value of the velocity is reached in the jet at a distance from the slot slightly higher than the width of the slot (1.25b). Under the action of the two recirculation zones, the velocity then decreases regularly and rapidly while the jet widens strongly: at a distance of $6 b$, the ratio $V / V_{\max }$ is only $0.4-0.5$ for the jet travelling in the pool. Figure 4 shows the velocity field and isovelocity contour lines of $V / V_{\max }$ in a plane parallel to the floor, where $V$ is the mean velocity vector in the $x-y$ plane.

Figure 6 shows the values of the dimensionless streamwise velocities $(u / \sqrt{2 g L S})$ in the immediate vicinity of the sidewall opposite the slot. The magnitude of the velocity is an indicator, in FP1, of the velocity of the principal recirculation zone, and in FP2 of the impact of the jet against the wall. These velocities should be kept as low as possible, especially for small species. For FP2 and a slope of $15 \%$, velocities in the vicinity of the wall reach magnitudes 

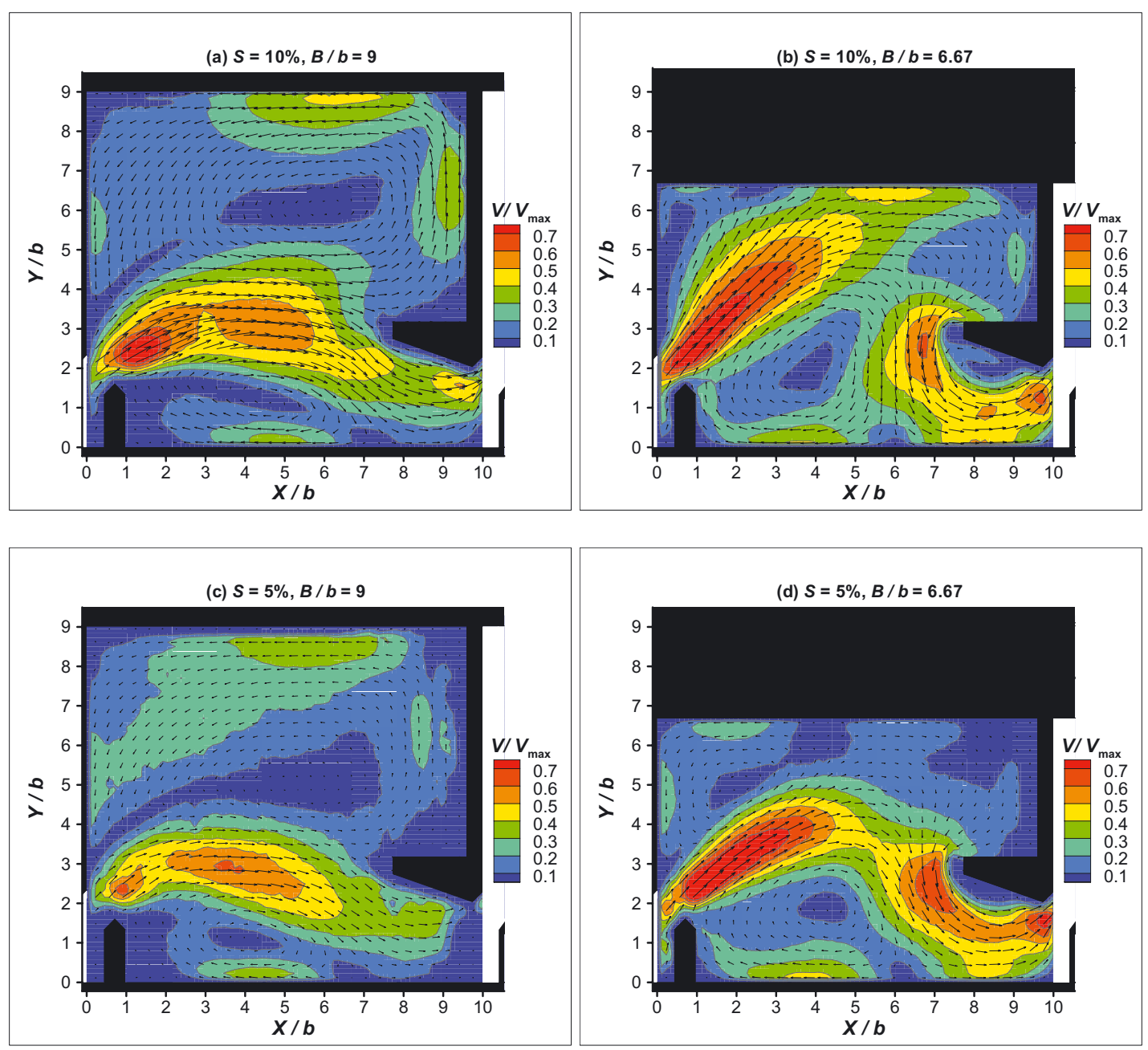

Figure 4

Isocontours of dimensionless velocities, $V / V_{\max }(B / b=9,6.67$ for $S=10 \%$ and $5 \%)$.

Figure 4

Isocontours de la vitesse adimensionnelle, $V / V_{\max }(B / b=9 ; 6,67$ pour $S=10 \%$ et $5 \%$ ).

of 0.50 to $0.55 V_{\max }$ depending on the value of the ratio $B / b$. For a slope of $10 \%$, the maximum velocities at the wall are between 0.45 and $0.50 V_{\max }$, and as low as $0.20-0.35 V_{\max }$ for a slope of $5 \%$. For $F P 1$ and $B / b=9$, the velocity at the wall in the recirculation zone reaches $0.4 V_{\max }$ (slopes of $15 \%$ and $10 \%$ ) and less than $0.15 V_{\max }$ for a slope of $5 \%$. For a prototype pool $3 \mathrm{~m}$ long, FP2 flow pattern and a slope of $15 \%$, velocities at the wall would be between 1.45 and $1.60 \mathrm{~m} \cdot \mathrm{s}^{-1}$ depending on the value of the ratio $B / \mathrm{b}$. For a slope of $10 \%$, velocities at the wall would be between 1.10 and $1.20 \mathrm{~m} \cdot \mathrm{s}^{-1}$, and as low as $0.35-0.60 \mathrm{~m} \cdot \mathrm{s}^{-1}$ for a slope of $5 \%$. For a ratio $B / b=9$ (FP1 flow pattern), velocity at the wall in the recirculation zone is approximately $1.15 \mathrm{~m} \cdot \mathrm{s}^{-1}$ (slope of $15 \%$ ), $0.95 \mathrm{~m} \cdot \mathrm{s}^{-1}$ (slope of $10 \%$ ) and less than $0.25 \mathrm{~m} \cdot \mathrm{s}^{-1}$ for a slope of $5 \%$.

Figure 7 represents the relative cumulative frequency distribution curves of the values of dimensionless velocities measured in a plane parallel to the floor. These polygons provide an estimate of the areas of the plane (or the part of the volume of the pool since the flow can be considered as two-dimensional) where fish might be able to rest. The shape of the curves does not vary with the discharge, but varies with the slope and with the flow pattern: for a given slope, the curves for pattern FP1 are located well above the curves for FP2. 
R.W. Wang et al.: Knowl. Managt. Aquatic Ecosyst. (2010) 396, 02

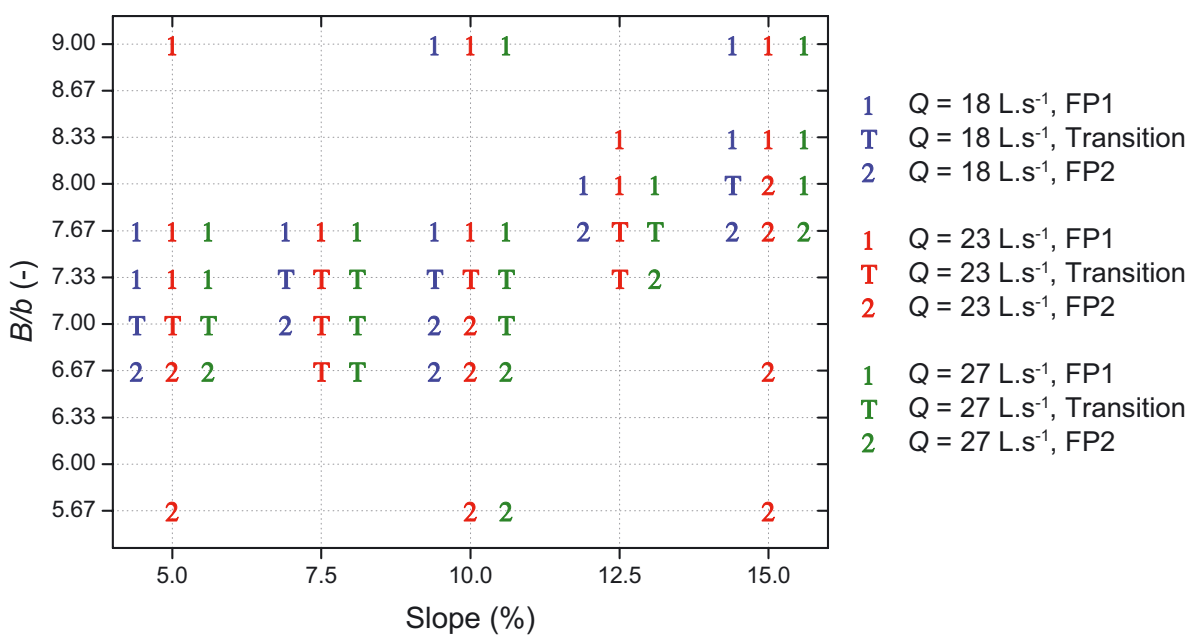

\section{Figure 5}

Flow topology for various slopes $(S)$ and pool width in terms of the ratio (B/b).

Figure 5

Topologie de l'écoulement pour différentes pentes $(S)$ et largeurs de bassin $(B / b)$.

(a) $S=5 \%$

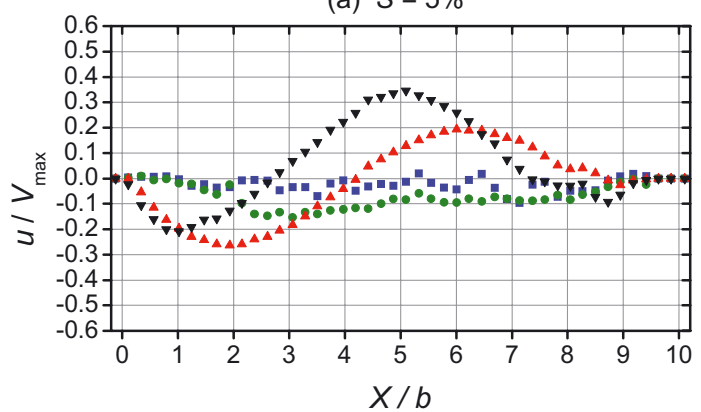

(c) $S=15 \%$

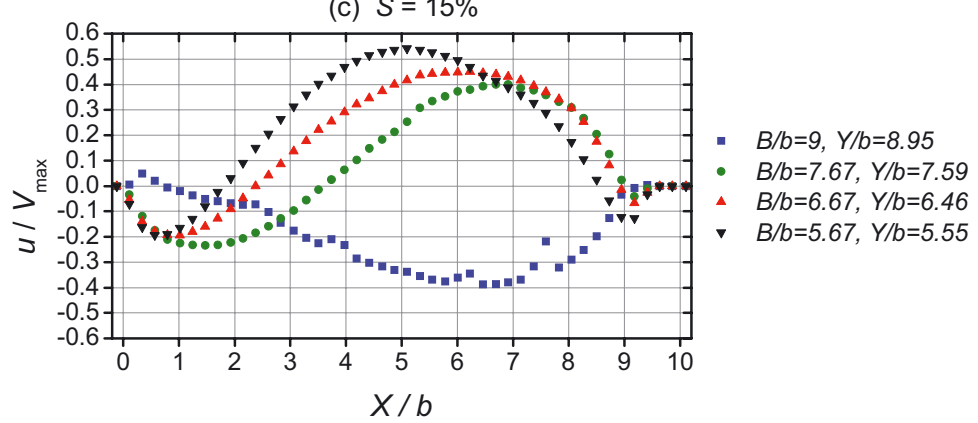

Figure 6

Normalized velocity in X-direction $(u / \sqrt{2 g L S})$ in the immediate vicinity of the side wall opposite the slot.

Figure 6

Vitesse normée suivant l'axe $X(u / \sqrt{2 g L S})$ au voisinage immédiat de la paroi latérale opposée à la fente. (b) $S=10 \%$

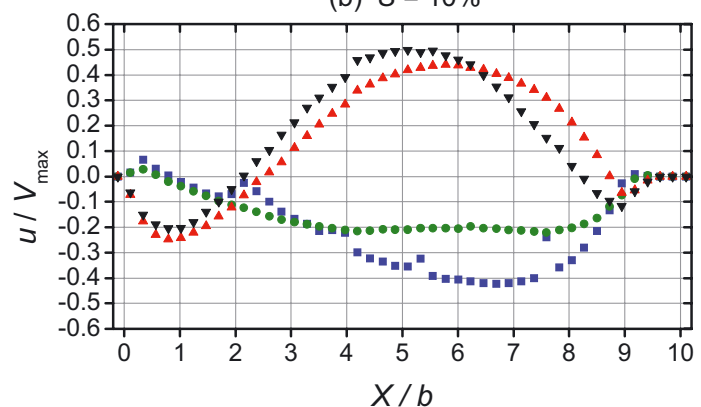

$B / b=7.67, Y / b=7.59$

$B / b=6.67, Y / b=6.46$

$x / b$ 
This means that potential zones for resting are larger in FP1 than in FP2. The average percentages of volume where the velocity is lower than $0.3 V_{\max }$ are respectively $0.70-0.75$ for FP1 and $0.50-0.55$ for FP2 at $S=10 \%$. These values reach approximately 0.80 for FP1 and $0.60-0.65$ for FP2 at $S=5 \%$.

The above results can be used in practice on a pool of specified dimensions. Table I shows the volume of the zones where the velocities are lower than $0.30 \mathrm{~m} \cdot \mathrm{s}^{-1}$ (here considered as a "resting zone" for small species) for a pool $3 \mathrm{~m}$ long and four different widths. The results, expressed in percentage of the pool volume and in absolute volume $\left(\mathrm{m}^{3}\right.$ per meter of water depth in the pool), show that the "resting zone" volume decreases significantly from $47.5 \%$ to $12.5 \%$ when the slope increases from $5 \%$ to $15 \%$. The effect of the width is less marked and surprisingly, for the slopes $5 \%$ and $10 \%$ (see Table I), the maximum "resting zone volume" clearly occurs when $B=2.3 \mathrm{~m}$ (and not for the largest width $B=2.7 \mathrm{~m}$ ).

\section{> CHARACTERISTICS OF TURBULENT FLOW IN POOLS}

Several relevant turbulence parameters have been identified in free surface flows. Turbulence parameters that are deemed most important to migrating fish include the turbulence intensity, strain, and turbulence length scales (Hotchkiss, 2002). Experiments have shown that fish have difficulty maintaining orientation during exposure to high turbulence intensity conditions, and at extremely high levels, shear stress can even cause bodily damage to fish (Odeh et al., 2002).

The turbulent kinetic energy, TKE $=1 / 2\left(\overline{u^{\prime 2}}+\overline{v^{\prime 2}}+\overline{w^{\prime 2}}\right)$ where $u^{\prime}, v^{\prime}$ and $w^{\prime}$ are fluctuating velocity components in longitudinal, transversal and vertical directions, is a local indicator of turbulence intensity and flow non-stationarity. It is a scalar quantity that seems ideally suited for representing the amount of fluctuation a fish experiences.

PIV measurements in planes parallel to the floor only give the part of the value of the TKE related to the components of the velocity $\left(u^{\prime}, v^{\prime}\right)$ in the $x-y$ plane and consequently underestimate the true value of the TKE. However the fluctuations of vertical components of the velocity in recirculation areas are limited, and the distribution of the TKE does not appear markedly three-dimensional (Tarrade, 2007).

Figure 8 shows the turbulent kinetic energy (TKE, or more exactly $\sqrt{\mathrm{TKE}}$ ), measured on the model for two width ratios $B / b=9$ and $B=6.67$, and for the three slopes tested, $5 \%$, $10 \%$ and $15 \%$. The maximum values are attained in the jet and on the edge of recirculation zones. The latter are subject to considerable fluctuations in velocity as a result of the beating movement of the jet.

The location and volume of zones where TKE remains low vary with both slope and width. For a given slope, the volume of zones with low values of turbulent energy increase considerably with pool width. Only the zone downstream of the small lateral baffle remains the same, irrespective of the conditions of width and slope, i.e. whatever the flow pattern.

As a general rule, maximum kinetic energies are relatively unaffected by width. The median turbulent kinetic energy values, irrespective of slope, for width ratios of $B / b=9,7.67,6.67$ and 5.67 , are $15.5 \mathrm{~cm} \cdot \mathrm{s}^{-1}, 17 \mathrm{~cm} \cdot \mathrm{s}^{-1}, 16.6 \mathrm{~cm} \cdot \mathrm{s}^{-1}$ and $16.3 \mathrm{~cm} \cdot \mathrm{s}^{-1}$ respectively. The first and third quartiles for these same four widths being respectively $11.3 / 19.5 \mathrm{~cm} \cdot \mathrm{s}^{-1}, 12.6 / 21.3 \mathrm{~cm} \cdot \mathrm{s}^{-1}$, $13.0 / 19.9 \mathrm{~cm} \cdot \mathrm{s}^{-1}$ and $12.5 / 19.5 \mathrm{~cm} \cdot \mathrm{s}^{-1}$.

On the other hand, turbulent kinetic energy varies significantly with the slope: the median kinetic energies, irrespective of width, for slopes of $5 \%, 10 \%$ and $15 \%$ are $13 \mathrm{~cm} \cdot \mathrm{s}^{-1}$, $16.2 \mathrm{~cm} \cdot \mathrm{s}^{-1}$ and $19.5 \mathrm{~cm} \cdot \mathrm{s}^{-1}$ respectively, while the first and third quartiles for the same three slopes are respectively $9.5 / 16.5 \mathrm{~cm} \cdot \mathrm{s}^{-1}, 12.7 / 19.5 \mathrm{~cm} \cdot \mathrm{s}^{-1}$ and $15.2 / 23.3 \mathrm{~cm} \cdot \mathrm{s}^{-1}$.

If we accept the hypothesis that the Froude similitude applies to TKE in the same way as to mean kinetic energy, then we can extrapolate the results to "prototype" pools with a slot width of $b=0.30 \mathrm{~m}$, pool length of $3 \mathrm{~m}$ long and widths of $B=2.7,2.3,2$ and $1.7 \mathrm{~m}$. Table II gives the median values of $\sqrt{\text { TKE }}$ in all the pools as well as the $\sqrt{\text { TKE }}$ in the low velocity zones $\left(<0.30 \mathrm{~m} \cdot \mathrm{s}^{-1}\right)$. The values of $\sqrt{\mathrm{TKE}}$ in these zones, which can be considered as resting zones 
(a) $S=5 \%$

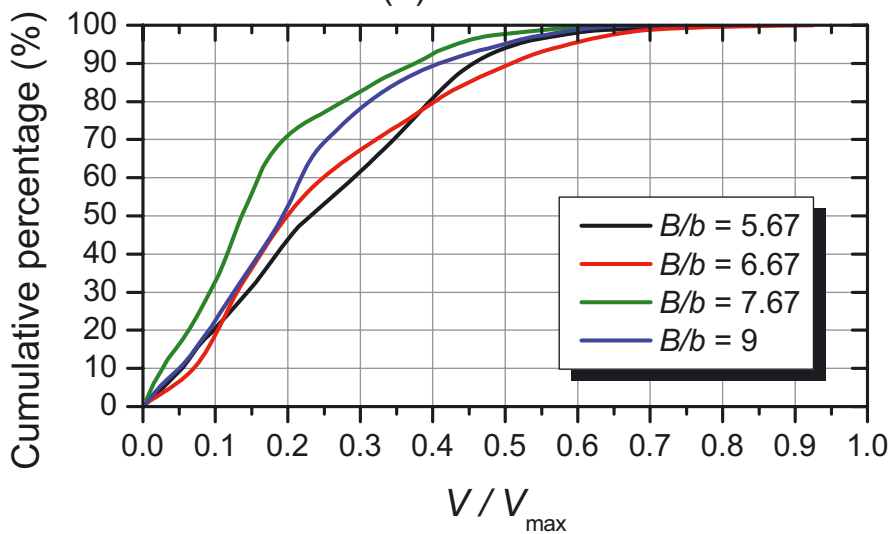

(b) $S=10 \%$

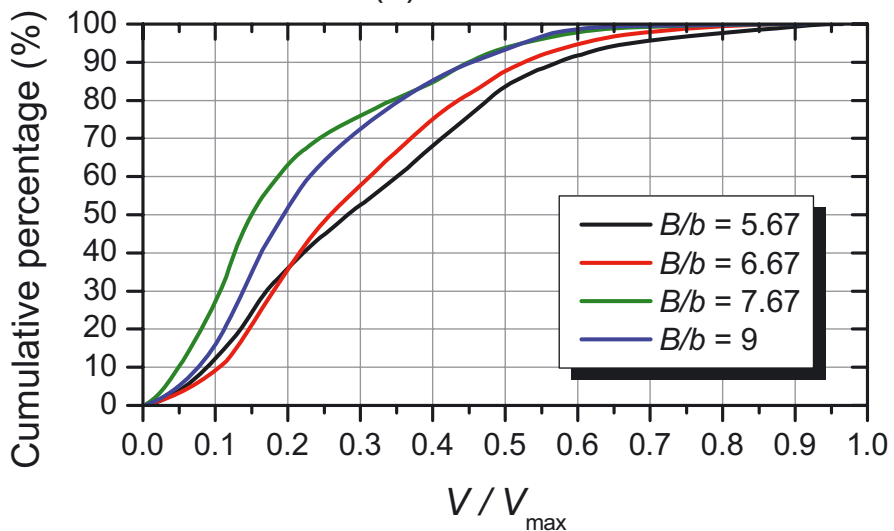

(c) $S=15 \%$

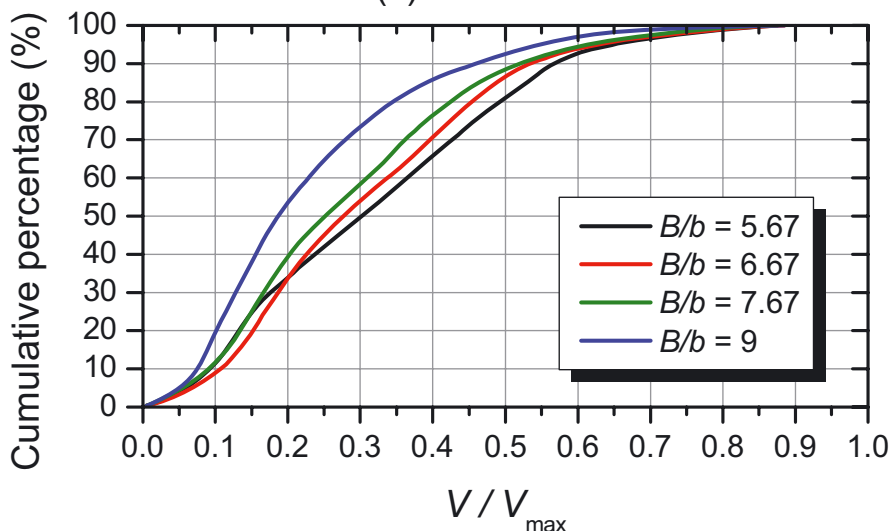

Figure 7

Relative frequency curves of $V / V_{\max }$ for various slopes and pool/slot width ratios (B/b).

Courbe des fréquences cumulées de $V / V_{\max }$ en fonction de la pente et de la largeur des bassins rapportée à la largeur de la fente $(B / b)$. 


\section{Table I}

Statistics for volume of resting zones where $V<0.3 \mathrm{~m} \cdot \mathrm{s}^{-1}$, in \% and absolute value for a $3 \mathrm{~m}$ long pool.

Tableau I

Statistiques des volumes des zones de repos $\left(V<0.3 \mathrm{~m} \cdot \mathrm{s}^{-1}\right)$, en $\%$ et en volume pour un bassin de $3 \mathrm{~m}$ de longueur.

\begin{tabular}{|l|c|c|c|c|c|}
\hline Slope & $B=2.7 \mathrm{~m}$ & $B=2.3 \mathrm{~m}$ & $B=2.0 \mathrm{~m}$ & $B=1.7 \mathrm{~m}$ & Mean \\
\hline $\mathbf{5 \%}$ & $42.7 \%(\mathrm{FP} 1)$ & $64.2 \%(\mathrm{FP} 1)$ & $42.1 \%(\mathrm{~T})$ & $36.1 \%(\mathrm{FP} 2)$ & $47.5 \%$ \\
& $\left(3.19 \mathrm{~m}^{3} \cdot \mathrm{m}^{-1}\right)$ & $\left(4.06 \mathrm{~m}^{3} \cdot \mathrm{m}^{-1}\right)$ & $\left(2.30 \mathrm{~m}^{3} \cdot \mathrm{m}^{-1}\right)$ & $\left(1.66 \mathrm{~m}^{3} \cdot \mathrm{m}^{-1}\right)$ & $\left(2.77 \mathrm{~m}^{3} \cdot \mathrm{m}^{-1}\right)$ \\
\hline $\mathbf{1 0 \%}$ & $22.4 \%(\mathrm{FP} 1)$ & $35.8 \%(\mathrm{FP} 1)$ & $12.2 \%(\mathrm{FP} 2)$ & $16.2 \%(\mathrm{FP} 2)$ & $22.4 \%$ \\
& $\left(1.67 \mathrm{~m}^{3} \cdot \mathrm{m}^{-1}\right)$ & $\left(2.26 \mathrm{~m}^{3} \cdot \mathrm{m}^{-1}\right)$ & $\left(0.67 \mathrm{~m}^{3} \cdot \mathrm{m}^{-1}\right)$ & $\left(0.75 \mathrm{~m}^{3} \cdot \mathrm{m}^{-1}\right)$ & $\left(1.34 \mathrm{~m}^{3} \cdot \mathrm{m}^{-1}\right)$ \\
\hline $\mathbf{1 5 \%}$ & $18.0 \%(\mathrm{FP} 1)$ & $10.9 \%(\mathrm{FP} 2)$ & $8.3 \%(\mathrm{FP} 2)$ & $10.6 \%(\mathrm{FP} 2)$ & $12.5 \%$ \\
& $\left(1.34 \mathrm{~m}^{3} \cdot \mathrm{m}^{-1}\right)$ & $\left(0.69 \mathrm{~m}^{3} \cdot \mathrm{m}^{-1}\right)$ & $\left(0.45 \mathrm{~m}^{3} \cdot \mathrm{m}^{-1}\right)$ & $\left(0.49 \mathrm{~m}^{3} \cdot \mathrm{m}^{-1}\right)$ & $\left(0.74 \mathrm{~m}^{3} \cdot \mathrm{m}^{-1}\right)$ \\
\hline
\end{tabular}

for smaller species, are in the region of $21-23 \mathrm{~cm} \cdot \mathrm{s}^{-1}, 24-30 \mathrm{~cm} \cdot \mathrm{s}^{-1}$ and $30-36 \mathrm{~cm} \cdot \mathrm{s}^{-1}$ for slopes of $5 \%, 10 \%$ and $15 \%$ and they represent $45 \%, 22 \%$ and $12 \%$ respectively of the volumes of these pools. The mean $\sqrt{T K E}$ seems to reach a maximum at the point of transition between the two flow patterns (FP1 and FP2), which can be explained by the instabilities that are more marked in the flow at this point.

\section{> TURBULENT KINETIC ENERGY, MAXIMUM AND AVERAGE VELOCITIES, VOLUMETRIC DISSIPATED POWER}

Statistical characteristics of $\sqrt{\mathrm{TKE}}$ measured in the model (in particular the first and third quartiles $\left(\sqrt{\mathrm{TKE}_{25}}\right.$ and $\left.\sqrt{\mathrm{TKE}} \mathrm{F}_{75}\right)$, which respectively represent the calmest and most agitated areas in and near the jet) can be related to parameters that are easily calculated, including theoretical maximum velocity $\left(V_{\max }\right)$ in the jet, average velocity $\left(V_{\text {deb }}\right)$, the ratio of the flow rate by cross-section of the flow in the pool $\left(Q /\left[B H_{b}\right]\right)$, and volumetric dissipated power $\left(P_{v}\right)$.

The following non-linear equation accounts for about $80 \%$ of the variance of $\sqrt{\mathrm{TKE}_{25}}$ :

$$
\sqrt{\mathrm{TKE}_{25}}=19.25 V_{\mathrm{deb}}^{0.28} V_{\max }^{0.72}\left(R^{2}=80 \%\right) \text {. }
$$

Insofar as we can accept the hypothesis that the Froude similitude can be applied to the TKE, this relationship should become independent of the dimensions of the fish pass.

$\sqrt{\mathrm{TKE}_{25}}$ can be found, depending on the value of the ratio $V_{\text {deb }} / V_{\max }(0.09-0.16$ depending on the values of $B / b$ and S), within a range of $17-20 \mathrm{~cm} \cdot \mathrm{s}^{-1}, 20-24 \mathrm{~cm} \cdot \mathrm{s}^{-1}, 24-28 \mathrm{~cm} \cdot \mathrm{s}^{-1}$ or $30-35 \mathrm{~cm} \cdot \mathrm{s}^{-1}$ for drops between pools of $15 \mathrm{~cm}, 20 \mathrm{~cm}, 30 \mathrm{~cm}$ and $45 \mathrm{~cm}$.

The volumetric dissipated power accounts for about $80 \%$ of the variance of $\sqrt{\mathrm{TKE}_{25}}$. The non-linear regression equation based on the results is as follows:

$$
\sqrt{\mathrm{TKE}_{25}}=3.13 P_{v}^{0.28}\left(R^{2}=79.5 \%\right) \text {. }
$$

However, this expression cannot be extrapolated to the dimensions of other fish passes, as the two terms of the expression do not have the same dimensions and for any given value of $\sqrt{\mathrm{TKE}_{25}}$, the corresponding value of $P_{V}$ will be higher for a small pool than for a larger one. The maximum velocity $V_{\max }$ accounts for $78 \%$ of the variance of $\sqrt{\mathrm{TKE}_{75}}$, although the average flow velocity $V_{\text {deb }}$ has no significant influence:

$$
\sqrt{\mathrm{TKE}_{75}}=21.8 V_{\max }^{0.69}\left(R^{2}=78 \%\right) .
$$

On the other hand, the dissipated energy only accounts for about $65 \%$ of the variance of the third quartile $\sqrt{\mathrm{TKE}_{75}}$. The equation for the adjusted model is:

$$
\sqrt{\mathrm{TKE}_{75}}=8.05 P_{v}^{0.18}\left(R^{2}=65 \%\right) \text {. }
$$


R.W. Wang et al.: Knowl. Managt. Aquatic Ecosyst. (2010) 396, 02
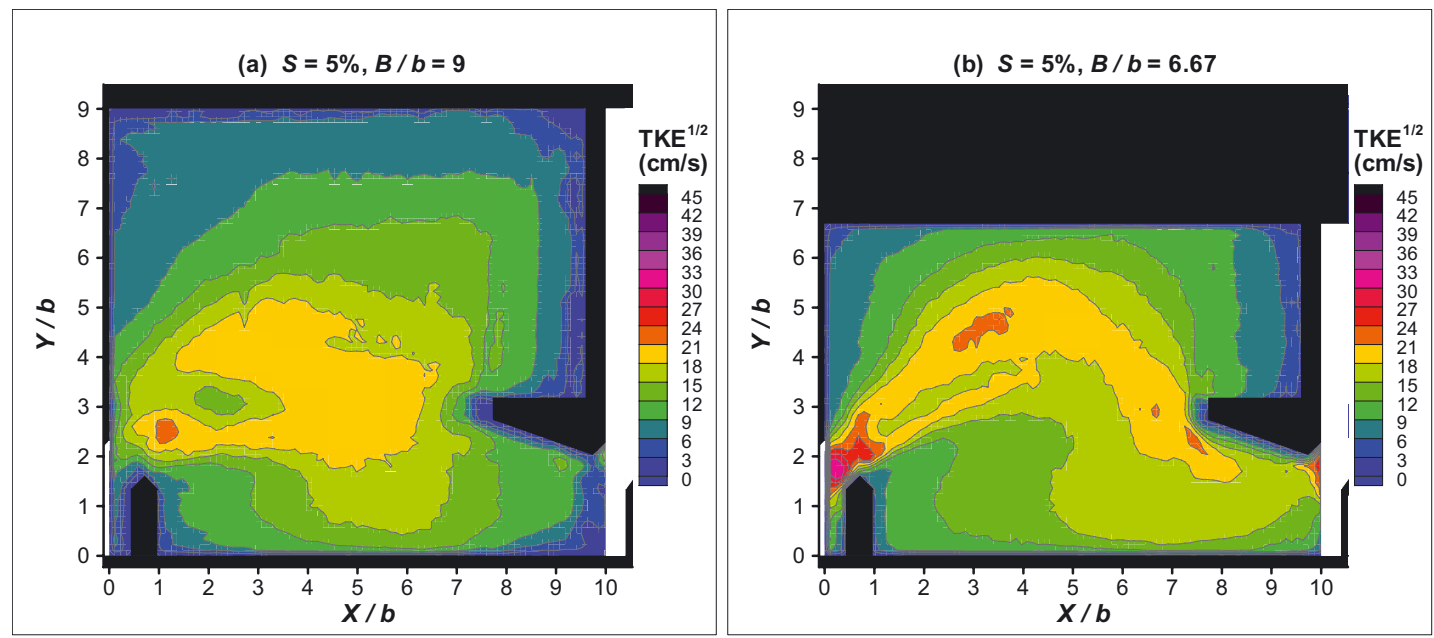

(c) $S=10 \%, B / b=9$

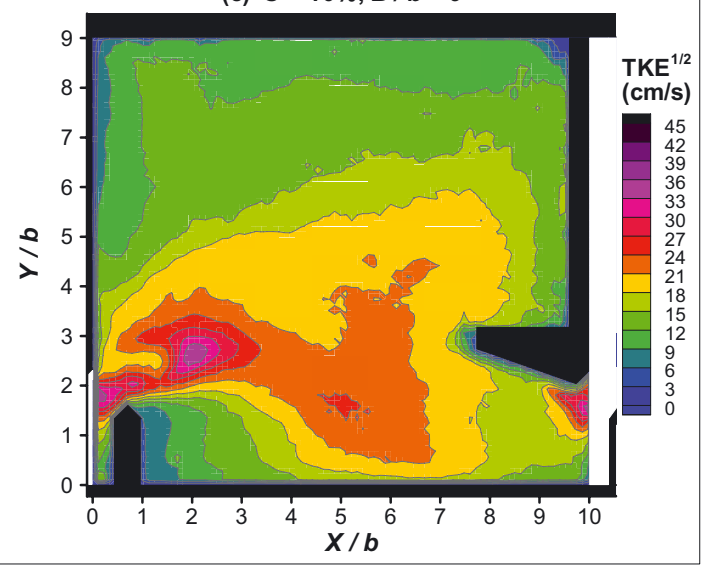

(d) $S=10 \%, B / b=6.67$

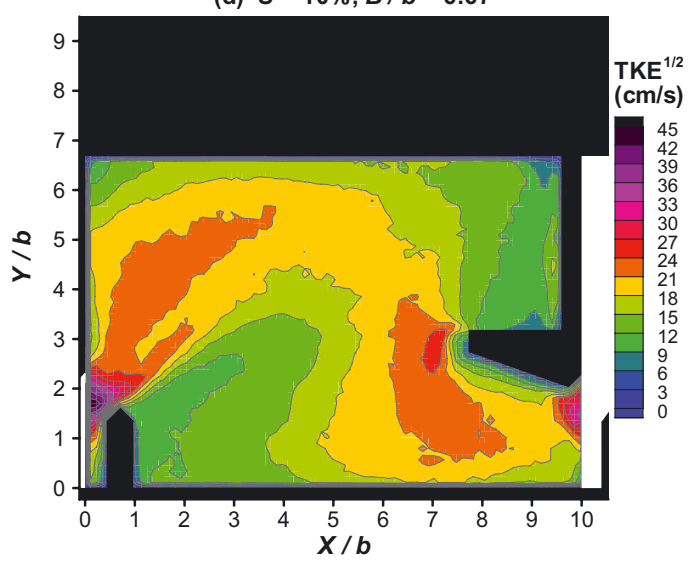

(e) $S=15 \%, B / b=9$

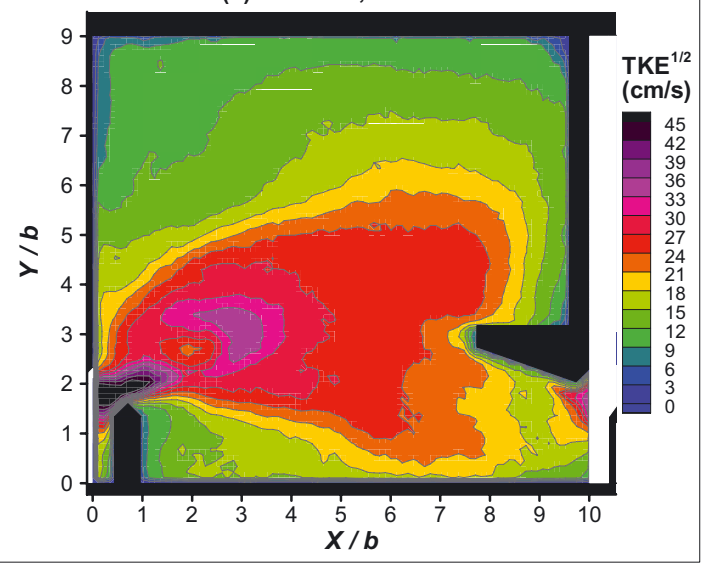

(f) $S=15 \%, B / b=6.67$

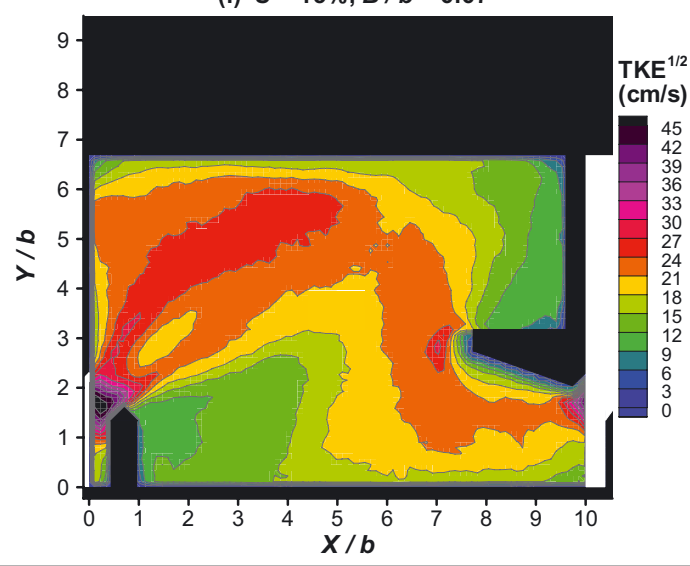

Figure 8

Turbulent kinetic energy $(\sqrt{\mathrm{TKE}})$ for $\mathrm{B} / \mathrm{b}=9$ and $6.67, \mathrm{~S}=5 \%, 10 \%$ and $15 \%$.

Figure 8

Énergie cinétique turbulente $(\sqrt{\mathrm{TKE}})$ pour $B / b=9$ et 6,$67 ; S=5 \%, 10 \%$ et $15 \%$. 


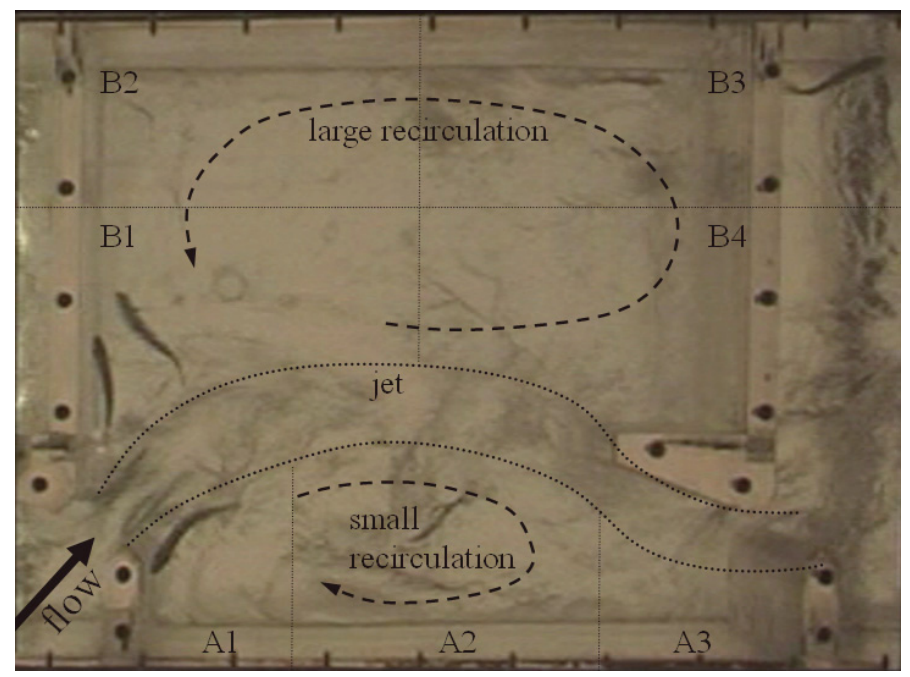

Figure 9

Snapshot of recorded videos in fish tests: $B / b=9, S=10 \%, Q=23 \mathrm{~L} \cdot \mathrm{S}^{-1}$.

Figure 9

Image vidéo des tests sur les poissons : $B / b=9, S=10 \%, Q=23 L \cdot S^{-1}$.

These results confirm that the turbulent kinetic energy values in the most turbulent zones (jet and near-jet) are linked above all to the value of the maximum velocity (or the slope), whereas TKE values in the calmest zones are linked not only to the maximum velocity value but also to the average velocity (i.e. the pool width).

\section{> FISH BEHAVIOUR IN THE FISH PASS}

Fish behaviour observed in the VSF was strongly affected by the flow and the structure. Figure 9 is a snapshot from videos recorded for $B / b=9, S=10 \%, Q=23 \mathrm{~L} \cdot \mathrm{S}^{-1}$. Here the pool is separated into sub-zones (A1-A3) within a small recirculation zone and (B1-B4) in the large recirculation zone in order to help to describe the trajectories of fish in more detail.

When fish entered the pool, most of them swam upstream along the sidewall and stayed behind the small baffle at the position of $A 1$. They frequently used this low flow velocity zone and stayed there from a few seconds to a few minutes, or even longer, and took advantage of the unsteady character of the jet to cross the slot. They used their burst speed only for the very short time required to pass through the slot, approximately one second. Sometimes fish moved between $A 1, A 2$, and $A 3$, or turned with the recirculation in $A 2$. They often used $A 3$ as a buffer to keep stable before moving to $A 1$. When fish were moving at $A 1$, the tail beat of fish had high frequency while they were close to the jet; the frequency of tail beat became much lower when they remained stationary just behind the baffle. This behaviour was observed very often in the tests.

The presence of fish in the large recirculation zone was mostly observed when fish returned from the upstream pool. They moved between different locations, e.g. both corners at the sidewall at B2 or B3, or at the corner between the cross-wall and the large baffle at B4, or moved around with the recirculation for a few seconds. However, any fish staying longer in the large recirculation zone were found at B1. Fish stayed at B1 and swam against the flow direction, i.e. the tail toward the slot, like the two fish shown in Figure 9, with the body almost perpendicular to the flow direction of the jet. Most of the time the tail beat of fish had great amplitude and low frequency; if fish came closer to the jet, they swam forward to keep away from it and high frequency tail beats were observed. Fish in the B1 recirculation zone accelerated to pass the slot either from the upper part of the zone when facing upstream in the lateral 


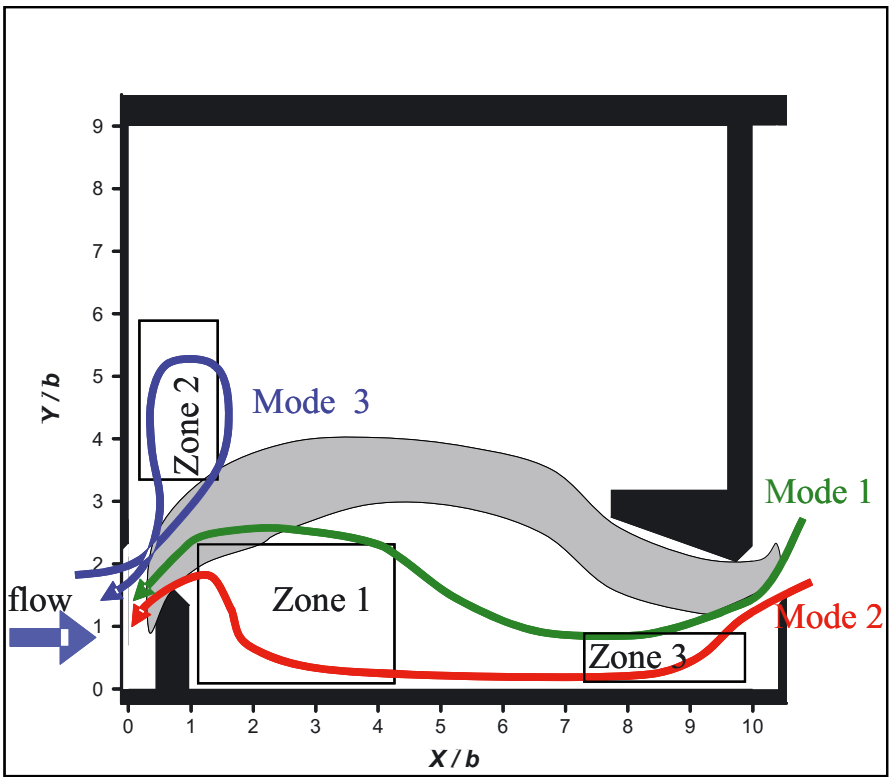

\section{Figure 10}

The most frequently used resting zones, Zone 1 and Zone 2, and the typical ascent modes of the brown trout tested in the experiments.

\section{Figure 10 \\ Localisation des zones de stabulation les plus fréquemment utilisées, Zone 1 et Zone 2, et trajectoires- types des truites lors des expérimentations.}

part of the jet, or else from the part of the recirculation zone immediately downstream of the side baffle by turning round to face the slot.

From the above observations it was clear that the two low flow velocity zones which were used most frequently by fish to stay for long periods were Zone 1 and Zone 2, shown in Figure 10. The dimensions of these two zones expressed as a ratio of the slot width, $b$, are $3.1 b$ by $2.4 b$ for Zone 1 and $1.3 b$ by $2.5 b$ for Zone 2 . In addition fish very often paused for a short period in Zone 3 before moving further into the pool. On average, the frequency of fish using Zone 1, Zone 2 and Zone 3 were 33\%, 19\% and 48\%, respectively, with median values of staying time of $11.5,30.5$ and 1 seconds.

Figure 10 also shows three typical modes of successful ascents of the tested brown trout. In Mode 1 fish entered and stayed for a short period behind the small baffle, soon passing through the slot to the next pool upstream (green line in the figure). In Mode 2 (most frequent) fish entered the pool and remained stationary in the flow in Zone 3 for a very short time (approximately 1 to 3 seconds) before moving to Zone 1 and staying there for several seconds or minutes. Before ascending by producing a burst of speed to pass through the slot, they remained behind the small baffle, very close to the water jet (red line). In Mode 3 fish came from the upstream pool into the large recirculation zone where they then remained in Zone 2. After a stay of several minutes or even longer, they moved close to the water jet and the crosswall, and then used a burst of speed (blue line) to continue ascending the fish pass.

\section{DISCUSSION}

\section{> DISCHARGE COEFFICIENT}

The discharge coefficient $\left(C_{d}\right)$ varies with both the slope $(S)$ and the pool width/slot width ratio $(B / b) . C_{d}$ decreases with increasing slope, the mean values ranging from 0.82 for $5 \%$ to 0.70 
for $15 \%$, which may account for the flow configuration: a visual examination of the streamlines shows that the contraction created by the baffle increases with the slope. The discharge coefficient also tends to diminish, but in a much less marked manner, as the $B / b$ ratio increases. The mean values for all slopes ranged from 0.79 for $B / b=5.67$ to 0.75 for $B / b=9$. The increase is more marked for the weakest slopes, $5 \%$ and $7.5 \%$, but less so for slopes equal to or greater than $10 \%$. These differences are not obviously explained by changing flow patterns in the pools.

For slopes between $5-7.5 \%$ and $B / b$ width ratios in the region of 7.67 , the discharge coefficients are about 0.80 to 0.85 . These values are significantly greater than those generally adopted when designing passes in France, the commonest values being around 0.65 to 0.75 (Larinier, 1992). These values, obtained from reduced-scale physical models, can be explained by the fact that most passes built in France since the 1980s were generally designed for large diadromous species (salmonids and particularly shad) and had sills in the lower part of the slots that could exceed $0.50 \mathrm{~m}$ in height. The sills cause extra vertical contraction and reduce the discharge coefficient very significantly to values in the region of 0.65 , particularly in shallower fish passes. Nowadays, most passes with vertical slots are designed without sills so as to ensure that the floor is continuous, thus facilitating the passage of smaller species. This need to encourage the passage of small species is also why there is a trend to decrease the head drop between pools. Contemporary passes most often have a head drop of 0.20-0.25 m or less, whereas they were generally $0.30 \mathrm{~m}$ in the VSFs built in the 1980 s. Underestimating flow coefficients at slots by 10 or $15 \%$ - and consequently flow rates - can have unexpected consequences. At the Gambsheim fish pass, the discharge coefficients were underestimated by approximately $12 \%$, which produced excessive velocity conditions at the narrower section of the counting window located in the upstream section of the pass. This has led to the need to modify the width of the upstream slots in order to reduce flow discharge inside the facility.

\section{$>$ TOPOLOGY}

Two different flow patterns FP1 and FP2 were observed, both of which had previously been identified by different authors (Wu et al., 1999; Puertas et al., 2004, Liu et al., 2006). However, these earlier studies considered only specific geometric designs (generally $L / b$ and $B / b$ ratios of 10 and 8) and either two or three different slopes. The present study looked at several shape ratios ( $B / b$ varying from 5.7 to 9$)$ and slopes varying from $5 \%$ to $15 \%$, and thus enabled us to pinpoint the transition between these two flow topologies and hence relate it to the two parameters, width and slope. For slopes varying between $5 \%$ and $7.5 \%$, the slopes found most frequently in large VSFs, the transition between FP1 and FP2 occurs when $B / b$ is close to 7 . For steeper slopes, greater than $10 \%$, found frequently in smaller fish passes such as those designed for trout, transition occurs for $B / b$ values between 7.5 and 8 .

In practical terms, the question that needs to be answered is whether a given configuration allows more fish to pass. Experience has shown that as far as possible the flow pattern should be bi-dimensional: high vertical velocity components are likely to perturb the fish's behaviour. If a jet strikes the side-wall of a pool too violently it can create swirl with a horizontal axis that generates high-velocity vertical components likely to perturb the behaviour of the fish (Figure 11). This is similar to the situation observed for smaller species in the helical currents that occur in Denil fish passes. On the other hand, particularly for smaller species, it is important to avoid the formation of recirculation zones that are too large and that drive the jet in the direction of the baffle, which can then cause the jet to short-circuit the pool. Indeed, it was precisely in order to direct the jet more successfully into the pools and avoid any excessive short-circuits that sills $20-30 \mathrm{~cm}$ high were originally recommended at the base of the slot (Andrew, 1990).

All of these points argue in favour of choosing flow patterns located in the transition zone, where the topology of the flow is not very marked, reducing the impact of the jet on the side wall and/or limiting the volume of the lateral recirculation zone. This would suggest that, as far as possible, $B / b$ ratios should be adopted of $7-7.5$ for slopes of $5-7.5 \%, 7.5-8$ for slopes 


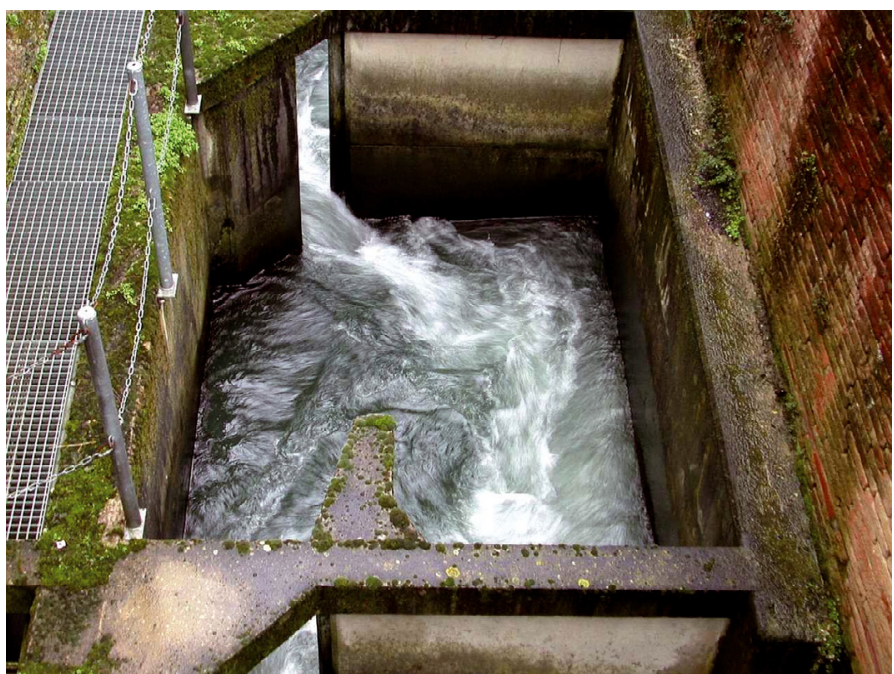

\section{Figure 11}

Visualization of swirls induced by the jet impacting the wall in a VSF with a low B/b ratio.

Figure 11

Visualisation des tourbillons induits par le jet impactant la paroi dans une VSF à faible valeur du rapport $B / b$.

of $10-12 \%$ and $8-8.5$, or even more, for steeper slopes. However, these values will depend on the shape factor $L / b$ and it is probable that these limits would need to be somewhat different in the case of shape factors differing significantly from 10 . The fact that the flow is non-stationary does not seem to perturb the fish: On the contrary, it seems that fish take advantage of this characteristic to pass through the slots.

In respect of flow conditions in the jet the results were consistent with earlier studies. The velocity decay in the jet was very rapid. At a distance of $6 b$, the ratio $V / V_{\max }$ for the jet travelling in the pool was around 0.4-0.5 depending on the slope and the pool-to-slot width ratio. These values lie between the values found by Wu et al. (1999) and Liu et al. (2006), respectively 0.4 and $0.5-0.6$.

In this study particular attention was paid to low-velocity flow zones that fish, especially smaller individuals, are likely to use for resting. Fish must be able to remain in a pool for short periods without excessive fatigue and this is a basic principle for the dimensioning of pools. Bell (1986) suggested that in a pool fish pass, velocity must be kept under $0.30 \mathrm{~m} \cdot \mathrm{s}^{-1}$ in $30 \%$ to $50 \%$ of the pool's volume. The dimensional example in Table I $(L=3 \mathrm{~m}$ and $b=0.30 \mathrm{~m})$ shows that this criterion is met whatever the width for a slope of $5 \%$ (36\% to $64 \%$ of the volume where $\left.V<0.30 \mathrm{~m} \cdot \mathrm{s}^{-1}\right)$. However, it is only met for a width of $2.3 \mathrm{~m}$ when the slope is $10 \%\left(36 \%\right.$ of the volume where $V<0.30 \mathrm{~m} \cdot \mathrm{s}^{-1}$ ) and is never met for a slope of $15 \%$. These flow conditions correspond to dissipated volumetric power values from 75 to $135 \mathrm{~W} \cdot \mathrm{m}^{-3}$ for a slope of $5 \%$ and $260 \mathrm{~W} \cdot \mathrm{m}^{-3}$ for a slope of $10 \%$. The latter value is beyond the limit of what is generally accepted as maximum volumetric dissipated power.

\section{Dissipated power and TKE}

Tests were intentionally carried out to include volumetric dissipated power values both below and well above the values commonly considered in the design of fish passes. The tests showed that flow patterns could be quite different even when volumetric dissipated power values were very close. Flow conditions could even become less favourable despite a significantly lower value for volumetric dissipated power that would normally suggest the contrary. As an example, for a slope of $5 \%$, flow conditions are clearly better when the width ratio is 
Table II

Median of $\sqrt{T K E}\left(\mathrm{~cm} \cdot \mathrm{s}^{-1}\right)$ in the whole pool and in the resting zones where $V<0.3 \mathrm{~m} \cdot \mathrm{s}^{-1}$ for a $3 \mathrm{~m}$ long pool.

Tableau II

Valeurs médianes de $\sqrt{\text { TKE }}\left(\mathrm{cm} \cdot \mathrm{s}^{-1}\right)$ dans les bassins et dans les zones de repos définies par $V<$ $0.3 \mathrm{~m} \cdot \mathrm{s}^{-1}$ pour un bassin de $3 \mathrm{~m}$ de longueur.

\begin{tabular}{|c|c|c|c|c|c|c|}
\hline \multicolumn{2}{|c|}{ Slope } & $B=2.7 \mathrm{~m}$ & $B=2.3 \mathrm{~m}$ & $B=2.0 \mathrm{~m}$ & $B=1.7 \mathrm{~m}$ & Mean \\
\hline \multirow{2}{*}{$5 \%$} & Whole & $21.9(\mathrm{FP} 1)$ & $25.6(\mathrm{FP} 1)$ & $28.5(\mathrm{~T})$ & $26.9(\mathrm{FP} 2)$ & 26.0 \\
\cline { 2 - 7 } & Rest & 21.6 & 22.1 & 22.8 & 21.3 & 21.8 \\
\hline \multirow{2}{*}{$10 \%$} & Whole & $30.5(\mathrm{FP} 1)$ & $35.5(\mathrm{FP} 1)$ & $34.1(\mathrm{FP} 2)$ & $30.8(\mathrm{FP} 2)$ & 32.6 \\
\cline { 2 - 7 } & Rest & 28.6 & 31.2 & 27.7 & 24.1 & 28.8 \\
\hline \multirow{2}{*}{$15 \%$} & Whole & $35.2(\mathrm{FP} 1)$ & $41.0(\mathrm{FP} 2)$ & $38.4(\mathrm{FP} 2)$ & $41.5(\mathrm{FP} 2)$ & 39.4 \\
\cline { 2 - 7 } & Rest & 34.4 & 35.5 & 30.2 & 31.9 & 33.1 \\
\hline
\end{tabular}

Table III

Volumetric dissipated power and slope for varying values of slot width and head loss between pools.

Tableau III

Puissance dissipée volumique et pente en fonction de la largeur de la fente et de la chute entre bassins.

\begin{tabular}{|l|c|c|c|}
\hline$b(\mathrm{~m})$ & $b=0.2 \mathrm{~m}$ & $b=0.3 \mathrm{~m}$ & $b=0.4 \mathrm{~m}$ \\
\hline Head loss $(\mathrm{m})$ & \multicolumn{3}{|c|}{$P_{v}\left(\mathrm{~W} \cdot \mathrm{m}^{-3}\right)$ and $\mathrm{S}(\%)$} \\
\hline $\mathbf{0 . 3}$ & $320 / 430(15 \%)$ & $215 / 285(10 \%)$ & $160 / 215(7.5 \%)$ \\
\hline $\mathbf{0 . 2 5}$ & $245 / 325(12.5 \%)$ & $160 / 215(8.3 \%)$ & $120 / 165(6.25 \%)$ \\
\hline $\mathbf{0 . 2 0}$ & $175 / 235(10 \%)$ & $115 / 155(6.7 \%)$ & $85 / 115(5 \%)$ \\
\hline $\mathbf{0 . 1 5}$ & $115 / 150(7.5 \%)$ & $75 / 100(5 \%)$ & $55 / 75(3.75 \%)$ \\
\hline $\mathbf{0 . 1 0}$ & $60 / 80(5 \%)$ & $40 / 55(3.3 \%)$ & $30 / 40(2.5 \%)$ \\
\hline
\end{tabular}

$B / b=7.6$ than when it is $B / b=9$, even though the dissipated power increases by $17 \%$. It was also found that values of turbulent kinetic energy in pools are linked primarily to the maximum velocity in the jet. On the other hand, the relationship between turbulent kinetic energy and $P_{v}$ depends on the dimension of the pools. This can easily be explained by the fact that $P_{V}$ defined as $P_{V}=\rho g Q \Delta H /\left(L B H_{b}\right)$ can also be expressed as:

$$
P_{V}=\rho V_{\mathrm{deb}} V_{\max }^{2} / 2 L \text {. }
$$

To improve fish passage, the first priority is thus to reduce the maximum velocity (i.e. the drop between pools), which will both make fish passage through slots easier and reduce turbulence intensity both within the jet and in the zones which are potential resting areas. This reduction of the maximum velocity will in turn result in lower values in the volumetric dissipated power, insofar as the length of the pools and the shape factors ( $L / b$ and $B / b$ ratios) that ensure acceptable flow patterns in the pools are maintained.

Reducing the dissipated power by adjusting only the volume of pools without reducing velocities will not necessarily improve flow conditions in the pools and therefore the ability of fish to clear the pass.

When designing fish passes, there is a tendency to adhere strictly to very precise maximum "admissible" values for volumetric dissipated power, whereas these values were originally only determined in order to impose broad limits on fish pass design. This study demonstrates the need to be relatively prudent about using these dissipated power criteria without also considering pool geometry and flow patterns.

In practice, the minimum width for the slot and the maximum drop between pools depend on the size of the largest individuals and the species with the weakest swimming capacity that must be accommodated. By maintaining the shape ratios $L / b=10$ and $B / b=7-9$, the previous relationship shows (Table III) that the dissipated power varies very significantly 
both with slot width and with the drop between pools. For a constant slot width, the slope is reduced proportionally to the drop between pools. For more "athletic" species, for which a drop between pools of $0.30 \mathrm{~m}$ and minimum slot widths of $0.30 \mathrm{~m}$ are generally used, the dissipated power of passes that respect the shape ratio studied are between 150 and $250 \mathrm{~W} \cdot \mathrm{m}^{-3}$. This is the case for many of the facilities in France designed for salmon. Slopes are in the region of 7.5 to $10 \%$. For shad, slot width is generally greater, in the region of $0.45-$ $0.50 \mathrm{~m}$, with the $L / b$ ratio being reduced to $8-9$ in order to preserve sufficient slope, while the flow is also reduced by placing a sill to mask part of the slot, apparently without any major adverse effect on the facility's efficiency for the target species. However, widening the slot can lead to non-optimum flow patterns, with the jet striking the side wall (FP2) with greater force. Maintaining a reasonable slope can be an insoluble problem when the target species include both very small species, requiring a relatively slight drop, and very large individuals requiring a particularly wide slot. This is the case in Australia, where the sizes of fish to be accommodated range between $40 \mathrm{~mm}$ and $1000 \mathrm{~mm}$. The drop between two pools cannot exceed $0.10 \mathrm{~m}$ and the width of the slot must be about $0.30 \mathrm{~m}$ (Stuart and Berghuis, 2002; Stuart et al., 2008). This results in passes with a shape ratio of $L / b=10$ and $B / b=7$, dissipated power of $40 \mathrm{~W} \cdot \mathrm{m}^{-3}$ and very low slopes in the region of $3.3 \%$. Here, one way of maintaining reasonable slopes would be to reduce the $L / b$ ratio considerably, even if this means using higher $B / b$ ratios.

\section{CONCLUSIONS}

This study has led to several original results, especially in relation to the influence of slope and of the shape factor $B / b$ on flow topology. It has demonstrated the advantages and limitations of particular experimental methods, e.g. the considerable advantage of using Particle Image Velocimetry to obtain very fine velocity fields, while conversely the method is limited when flow becomes clearly three-dimensional. While Acoustic Doppler Velocimetry can show the three components and the turbulent fluctuations of velocity, exploring these velocity and turbulence fields in a pool is very time-consuming, particularly without an automated carrying table.

More fundamentally, it would be helpful to verify the pertinence and limitations of the Froude similitude for turbulent kinetic energy, since this issue has not been clearly settled in the literature.

The tests enabled us to explore the influence of slope as well as of the shape ratio $B / b$ on flow characteristics, although only for a single value for the $L / b$ shape factor. From a practical point of view, it is suggested that testing lower values of the $L / b$ shape ratio, in the region of $7-8$, may determine that it is possible to significantly reduce maximum velocities while remaining within a range of slopes that are acceptable in practice. It should be remembered that the slope of a fish pass is a key element in its cost, considering that it determines the total length of the installation, and that any reduction in overall length can make a significant saving.

Studies should also investigate the "manipulation of turbulence" in pools (Mallen-Cooper et al., 2008; Tarrade et al., 2008), for example by installing obstacles in front of the jet to improve hydraulic conditions in the pools, i.e. reducing velocities in recirculation zones (FP 1) and impact velocities against walls (FP 2).

Computer models can be of considerable use, particularly as a substitute for tests on scale models that always prove onerous. However, models should first be verified to ensure that they are capable of faithfully reproducing the different flow configurations and particularly the transition from one flow pattern to the next. This requires a clear prior statement of cost functions that are realistic in biological terms and must look beyond such very general criteria as maximum velocities, kinetic energy or vorticity, considering that fish generally do not explore more than a small proportion of pools. Modelling, whether physical or numerical, must therefore go hand in hand with an improvement in our knowledge of the behaviour of fish in pools and in particular the use they make of the different flow zones. While our models are more and more powerful, our limited knowledge of fish behaviour means that they cannot be exploited fully, considering that fish behaviour is highly variable and depends 
first on species and then, within a given species, on individual size. It is vital that we increase our understanding of the range of fish reactions to local hydrodynamics. Until we acquire more knowledge in this area, there is a danger that the use of models will remain a technical tour de force of little practical use.

\section{Notation}

The following symbols are used in this paper:

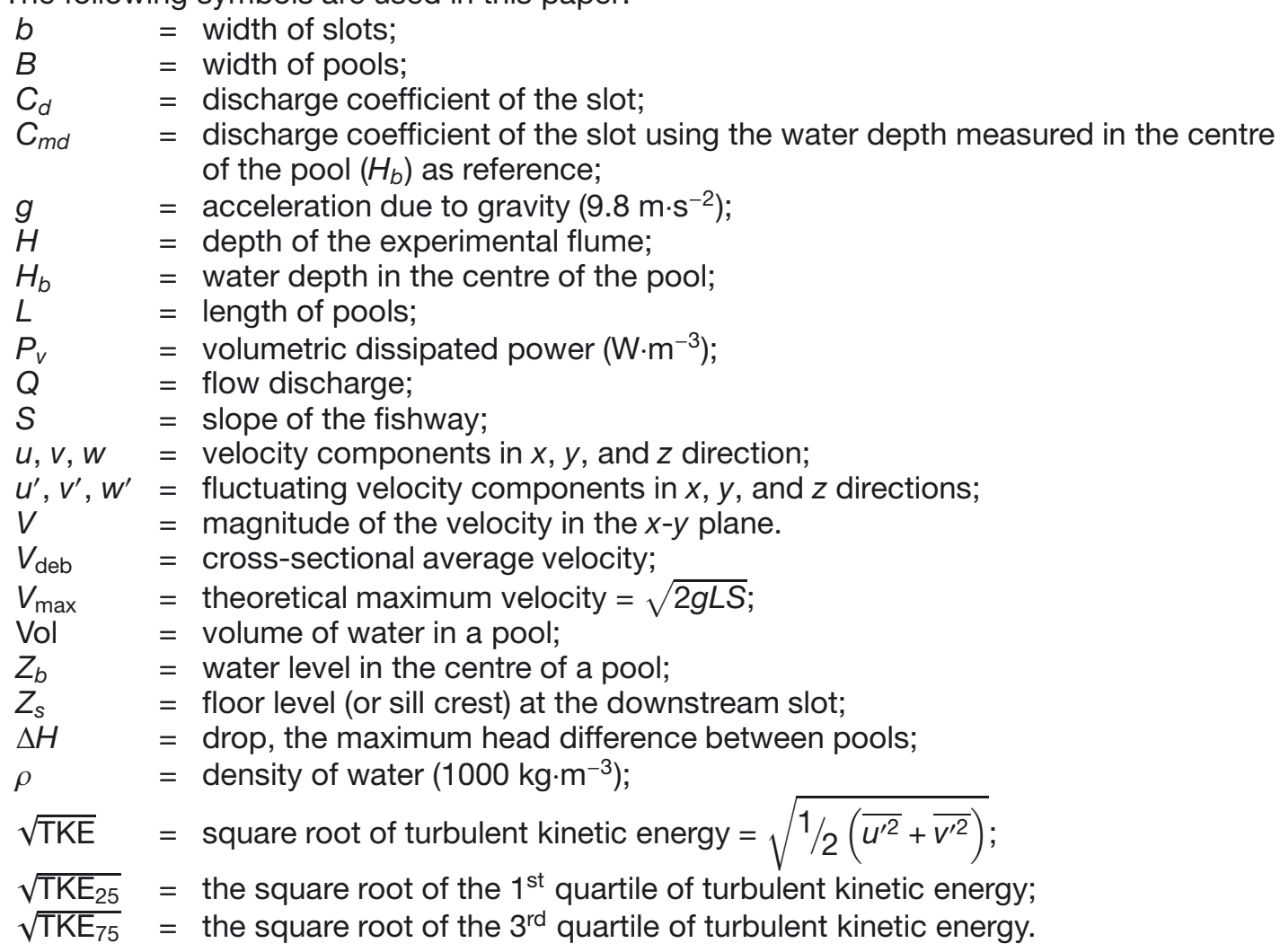

\section{REFERENCES}

Andrew F., 1990. The use of vertical-slot fishways in British Columbia, Canada. Proceedings of the International Symposium on Fishways '90 in Gifu, Japan, 267-274.

Barrett J. and Mallen-Cooper M., 2006. The Murray River's 'Sea to Hume Dam' fish passage program: progress to date and lessons learned. Ecol. Manage. Res., 7, 3, 173-183.

Bates K., 2000. Fishway guidelines for Washington State, Washington Department of Fish and Wildlife, $57 \mathrm{p}$.

Bell M., 1986. Fisheries Handbook of engineering requirements and biological criteria - Fish Passage Development and Evaluation Program, US Army Corps of Engineers, North Pacific Division Portland, Oregon, $290 \mathrm{p}$.

Goring D.G. and Nikora V.I., 2002. Despiking acoustic Doppler velocimeter data. J. Hydraul. Eng., 128, $1,117-126$.

Guiny E., Ervine D.A. and Armstrong J.D., 2005. Hydraulic and biological aspects of fish passes for Atlantic salmon. J. Hydraul. Eng., 131, 7, 542-553.

Hotchkiss R., 2002. Turbulence investigation and reproduction for assisting downstream migrating juvenile salmonids, Part I; BPA Report DOE/BP-00004633-I, Bonneville Power administration, Portland, Oregon, $138 \mathrm{p}$.

Kynard B., Horgan M., Pugh D., Henyey E. and Parker T., 2008. Using juvenile sturgeons as a substitute for adults: a new way to develop fish passage for large fish. American Fisheries Society Symposium, 61, 1-21.

Larinier M., 1983. Guide pour la conception des dispositifs de franchissement des barrages par les poissons migrateurs. Bull. Fr. Piscic., Hors Série, 39 p. 
Larinier M., 1992. Passes à bassins successifs, prébarrages et rivières artificielles. Bull. Fr. Pêche Piscic., 326/327, 45-72.

Larinier M., Travade F. and Porcher J.P., 2002. Fishways: biological basis, design criteria and monitoring. Bull. Fr. Pêche Pisc., 364, 1-208.

Liu M., Rajaratnam N. and Zhu D., 2006. Mean flow and turbulence structure in vertical slot fishways. J. Hydraul. Eng., 132, 8, 765-777.

Mallen-Cooper M., Zampatti B., Stuart I. and Baumgartner L., 2008. Innovative fishways: manipulating turbulence in vertical-slot design to improve performance and reduce cost, Murray-Darling Basin Commission, $19 \mathrm{p}$.

Odeh M., Noreika J., Haro A., Castro-Santos T. and Cada G., 2002. Evaluation of the effects of turbulence on the behaviour of migratory fish, Final Report, to Bonneville Power Administration, Project No. $200005700,55 \mathrm{p}$.

Puertas J., Pena L. and Teijeiro T., 2004. An experimental approach to the hydraulics of vertical slot fishways. J. Hydraul. Eng., 130, 1, 10-23.

Rajaratnam N., Van der Vinne G and Katopodis C., 1986. Hydraulics of vertical slot fishways. J. Hydraul. Eng., 112, 10, 909-927.

Rajaratnam N., Katopodis C. and Solanki S., 1992. New designs for vertical slot fishways. Can. J. Civ. Eng., 19, 3, 402-414.

SonTek, 1997. Acoustic Doppler velocimeter technical documentation, Version 4.0, San Diego.

Stuart I.G. and Berghuis A.P., 2002. Upstream passage of fish through a vertical-slot fishway in an Australian subtropical river. Fish. Manag. Ecol., 9, 111-122.

Stuart I.G., Zampatti B.P. and Baumgartner L.J, 2008. Can a low gradient vertical-slot fishway provide passage for a lowland river fish community? Mar. Freshw. Res., 59, 332-346.

Tarrade L., 2007. Étude des écoulements turbulents dans les passes à poissons à fentes verticales. Adaptation aux petites espèces. Doctoral thesis, Université de Poitiers, Faculté des Sciences Fondamentales et Appliquées, $217 \mathrm{p}$.

Tarrade L., Texier A., David L., Pineau G. and Larinier M., 2006. An experimental study of turbulent flow in vertical slot fishways. 12th International Symposium on Flow Visualization, German Aerospace Center (DLR), Göttingen, $12 \mathrm{p}$.

Tarrade L., Texier A., David L. and Larinier M., 2008. Topologies and measurements of turbulent flow in vertical slot fishways. Hydrobiologia, 609, 177-188.

Wahl T.L., 2000. Analysing Data using WinADV, 2000. Proc. 2000 Joint Conference on Water Resources Planning and Management, American Society of Civil Engineering, Minneapolis, $10 \mathrm{p}$.

Wu S., Rajaratnam N. and Katopodis C., 1999. Structure of flow in vertical slot fishways. J. Hydraul. Eng., 125, 4, 351-360. 